\title{
Intestinal Tuberculosis or Crohn's Disease: A Diagnostic Challenge Case Report
}

Ali Najafpour ${ }^{1}$, Leila Hamzelou' ${ }^{2}$ Babak Sayad $^{3}$

1.Medical student, Student research Committee, Faculty of Medicine, Kermanshah University of Medical Sciences. Kermanshah, Iran. ORCID ID: 0000-0002-7677-0760.

2. General Practitioner, Infectious Diseases Research Center, Kermanshah University of Medical Sciences. Kermanshah, Iran. ORCID ID: 0000-0003-0329-7551.

3.Professor, Department of Infectious Disease, School of Medicine, Kermanshah University of Medical Sciences, Kermanshah, Iran., (Corresponding Author), Tel: 083-34274618. Email: Babaksayad@ kums.ac.ir, ORCID ID: 0000-00018686-9986.

\begin{abstract}
Background and Aim: Crohn's disease is a chronic idiopathic disease in the category of gastrointestinal tract inflammation without any obvious reason. Clinical signs include abdominal pain, and diarrhea, which may be accompanied by a fistula or intestinal obstruction. Differential diagnosis of Crohn's disease and intestinal tuberculosis is a complex and difficult challenge.
\end{abstract}

Case presentation: The patient was a 70-year-old woman who had been hospitalized due to fistulas with 4 years of discharge in the left inguinal and gluteal area. The patient's vital signs were stable, and she did not report any fever, chills, or gastrointestinal symptoms. Diagnostic tuberculosis procedures were performed for this patient and despite the lack of evidence in favor of intestinal tuberculosis, experimental tuberculosis treatment was started for him. Despite 10 months of anti-tuberculosis treatment, the symptoms and fistulas of the patient did not recover in 2016. On spiral computed tomography scan of the lung and mediastinum without injection, the presence of cardiomegaly, evidence of ground-glass was seen along with an increased thickness of the interlobular septa in the middle lobe of the right lung and ground glass opacities at the base of both lungs. Since the patient had typical intestinal tuberculosis symptoms, discharge cultivation and smear were performed and it did not grow on Mycobacterium tuberculosis bacillus acid staining. The patient underwent biopsy with MR Enterography, and Crohn's diagnosis was confirmed. The patient was treated with Metronidazole, Ciprofloxacin, and a combination of Azathioprine and Infliximab.

Conclusion: According to the rare case reported, advanced diagnostic measures should be taken in dealing with patients with intestinal tuberculosis or Crohn's disease.

Keywords: Crohn's disease, Differential diagnosis, Intestinal tuberculosis

Received: July 21, 2020

Accepted: Dec 20, 2020

How to cite the article: Ali Najafpour, Leila Hamzelou, Babak Sayad. Intestinal Tuberculosis or Crohn's Disease: A Diagnostic Challenge Case Report. SJKU 2021;26(1):139-146.

Copyright (C) 2018 the Author (s). Published by Kurdistan University of Medical Sciences. This is an open access article distributed under the terms of the Creative Commons Attribution-Non Commercial License 4.0 (CCBYNC), where it is permissible to download, share, remix, transform, and buildup the work provided it is properly cited. The work cannot be used commercially without permission from the journal 


\title{
سل روده يا بيمارى كرون، يك حالش تشخيصى: گزارش مورد
}

\author{
على نجف يور'، ليلا حمزه لو'، بابك صيادَ"

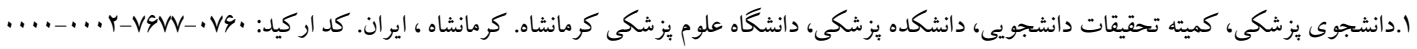

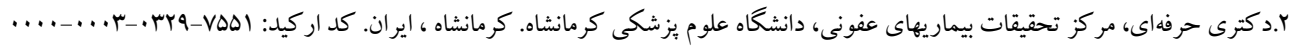

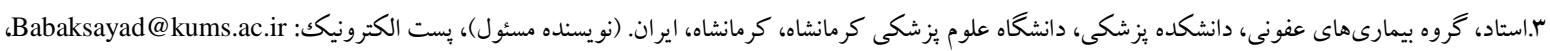

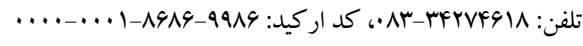

جָكيله

زمينه و هدف: بيمارى كرون يكك بيمارى مزمن ايديوياتيكك در دسته بيمارىهاى التهابى دستخاه گوارش بدون علت مشخص

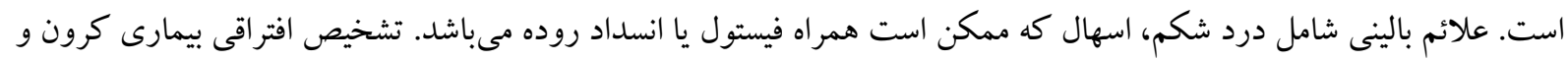
سل رودهاى جالشى بيجِيده و دشوار است.

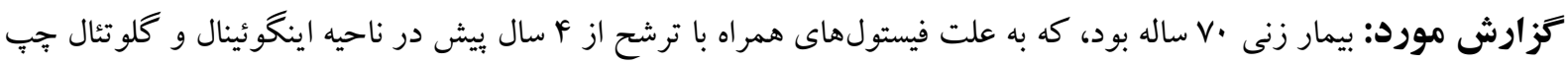

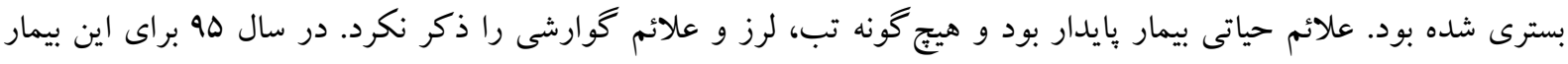

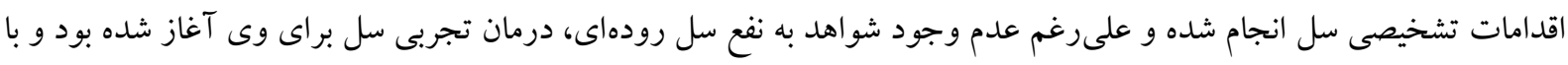

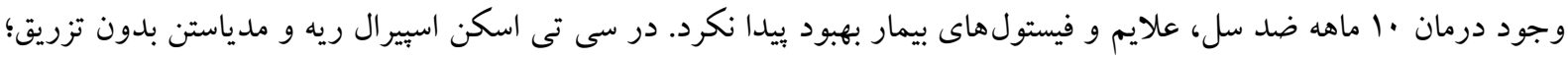

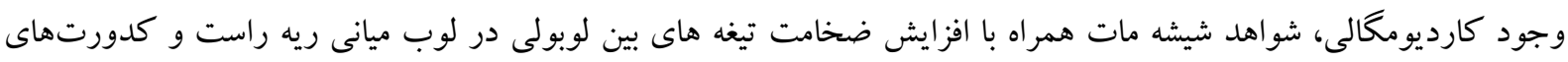

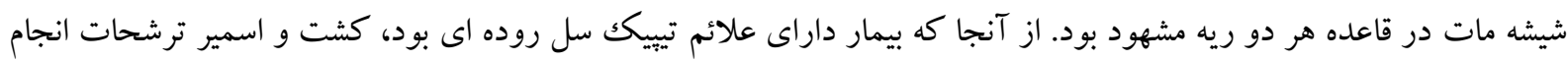

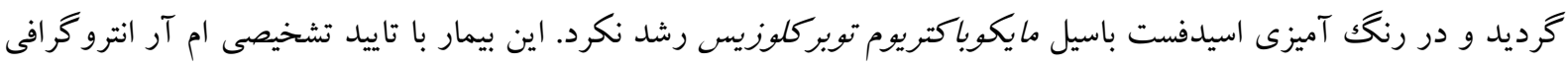

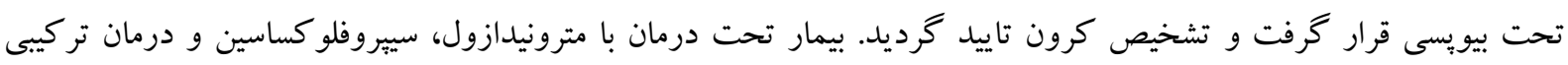

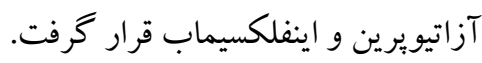
نتيجه كيرى: با توجه به مورد نادر كزارش شده، در برخورد با بيماران سل رودهاى يا كرون اقدامات تشخيصى تكميلى انجام كردد. وازه هاى كليدى: بيمارى كرون، تشخيص افتراقى، سل روده اى

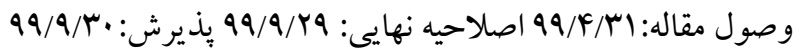


مى تواند هر قسمتى از دستخاه گگارش از جمله دهان، مرى،

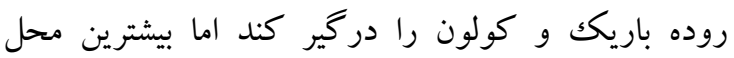
درگيرى بخش انتهايى روده باريك و و ابتداى كولون

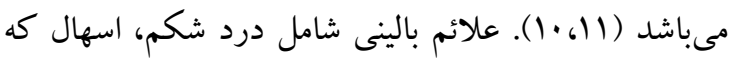

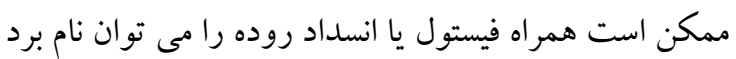

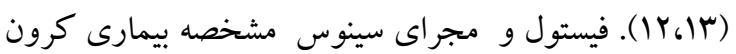

است كه در يكك سوم بيماران رخ مىدهد (rا).

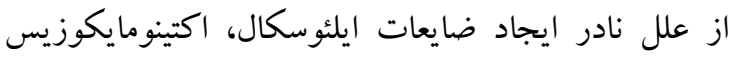

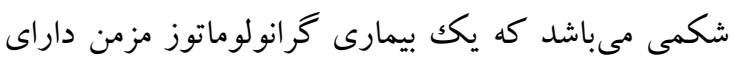
علائم بالينى مشابه تومورهاى كارسينوئيد، كرون و سرطان

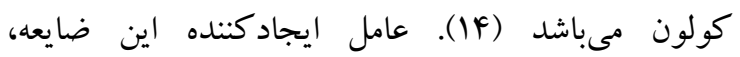

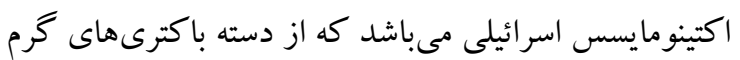
مثبت، بىهوازى و داراى رشد آهسته است و بخشى از فلور

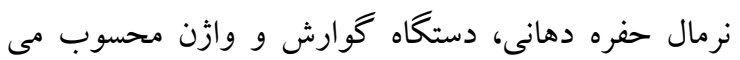
شود (ها). اكثر موارد اكتينومايكوزيس خارج شكمى بوده

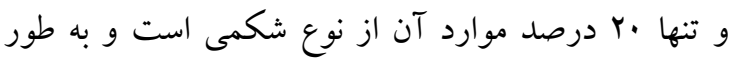

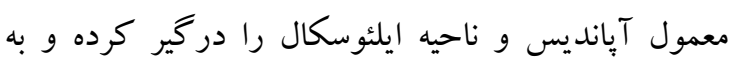
صورت تودهى قابل لمس و فيستول بروز كند (19). تشخيص سل رودهاى خصوصا در غياب عفونت فعال ريوى، جالشى بزرگك محسوب مىشود. زيرا ITB علائم بسيارى از بيمارىهاى شكمى مانند تومورهاى شكمى، آبسهاى بـاى

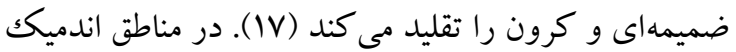
از نظر سل نظير غرب ايران امكان بروز سل رودهاى وجود

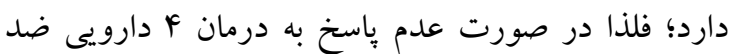
سل، بايد بلافاصله بيمار را از نظر كرون مورد بررسى قرار

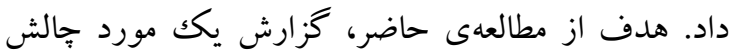
تشخيصى سل رودهاى و كرون مىباشد.

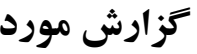

بيمار زنى •V ساله اهل و ساكن سنتدج در شمال غربى

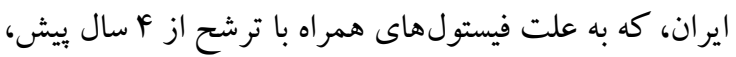

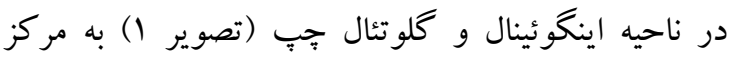

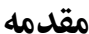

تقريبا يك سوم جمعيت جهان به مايكوباكتريوم توبركلوزيس آلوده هستند و در خطر ابتلا به بيمارى سل قرار دارند. هر ساله حدود 9 ميليون (Tuberculosis, TB) نفر به سل فعال مبتلا مىشوند و حدود ه/ اميليون نفر در اثر اين بيمارى فوت مى كنند (1). سازمان جهانى بهداشت در

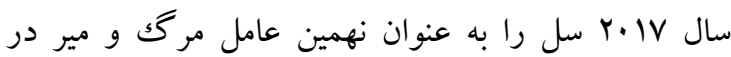
سراسر جهان معرفى نمود (Y). بررسىهاى مختلف نشان

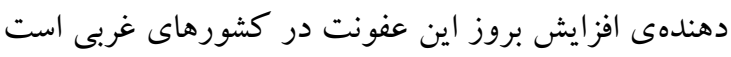

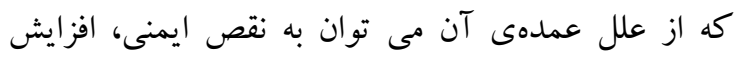

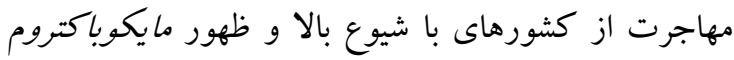

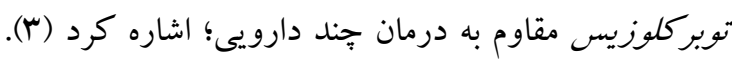

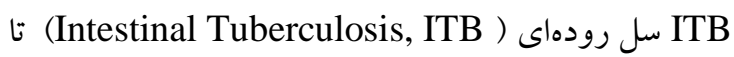
دهه .199 ميلادى از علل اصلى انسداد روده باريك دوراي

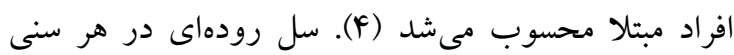

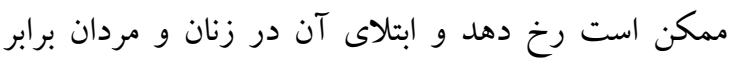

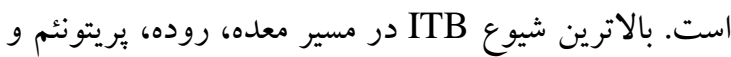
بعد از آن لنف نودهاى مزانتر است. تظاهرات راديولوزيكك ITB، افزايش ضخامت جدار روده، ندولاريتى و افزايش

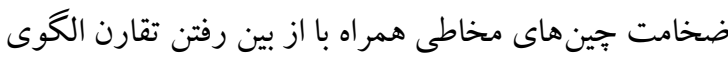

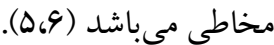
Inflammatory bowel بيمارىهاى التهابى روده (disease, IBD است كه شامل كوليت اولسراتيو و كرون مىباشد (V). بروز اين بيمارىها در سالهاى اخير افزايش يافته است، به طوريكه ميزان بروز كوليت اولسراتيو و كرون به ترتيب IVF-YFV و مورد در IIF-YNA

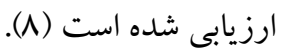

بيمارى كرون (Crohn Disease, CD) يك بيمارى مزمن

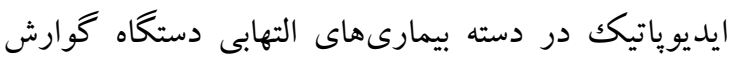
بدون علت مشخص است (9). كرون در گروه سنى بالا برخلاف بيماران جوان، در زنان شايع تر است. بيمارى كرون

هملم علمى دانشكاه علوه بِزشكى كردستان / دوره بيست و شش / فروردين و ارديبهشت م.ع|| 
زنجيره بِيمراز انجام شده از ترشحات فيستولها،

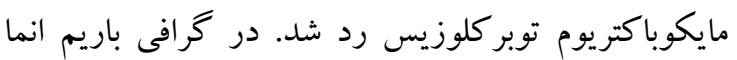

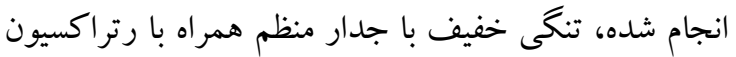

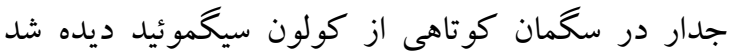
(تصوير r). در كولونوسكويى انجام شده با اسكوٍ اطفال

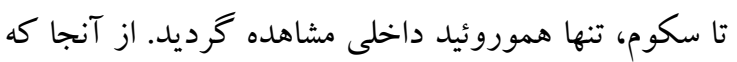

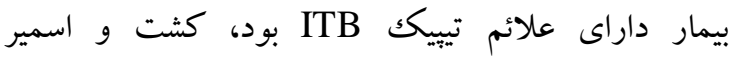
ترشحات انجام شد و در رنگك آميزى اسيدفست باسيل

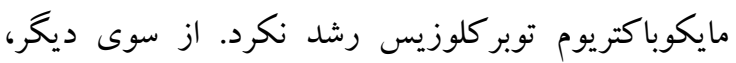

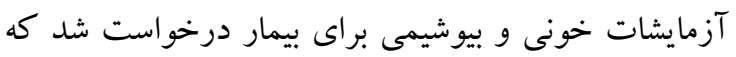
نتايج آن به شرح زير است:

W.B.C $=\Delta / q \times 1 \cdot{ }^{r} / \mathrm{mm}^{r}$

R.B.C $=r / . \Delta \times 1 .{ }^{9} / \mathrm{mm}^{r}$

$\mathrm{Hb}=11 / 9 \mathrm{gm} / \mathrm{mm}^{r}$

$\mathrm{Hct}=r q / r \%$

M.C. $V=\wedge 9 / \uparrow \mathrm{fL}$

M.C.H $=$ rN/9 Pgm

PLT $=r \mu r \times 1 . r / \mathrm{mm}^{r}$

$\mathrm{ESR}=\Delta 1 \mathrm{~mm} / \mathrm{hr}$

Urea $=\Delta F \mathrm{mg} / \mathrm{dL}$

Creat $=1 / 1 \mathrm{mg} / \mathrm{dL}$

$\mathrm{Na}=|f| \mathrm{mEq} / \mathrm{L}$

$\mathrm{K}=\mathrm{r} / \Delta \mathrm{mEq} / \mathrm{L}$

با مشاوره انجام شده با سرويس فوق تخصصى گوارش و كبد مركز آموزشى درمانى امام رضاع) كرمانشاه، بيمار

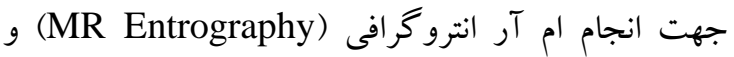
تاييد تشخيص كرون به مركز آموزشى درمانى دكتر

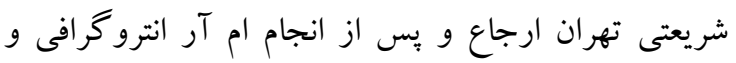
براى بيمار ايلوكولونوسكويى انجام و بيويسى از ترمينال ايلئوم جهت بررسى باتولوزى تهيه و تشخيص قطعى كرون بئن

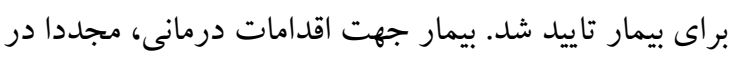

آموزشى درمانى امام رضا (ع) شهر كرمانشاه، مراجعه كرده

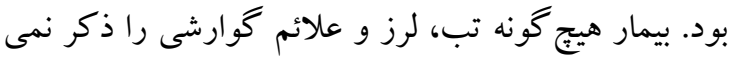
كرد و علائم حياتى وى ثابت بود. بيمار سابقه قبلى فيستول

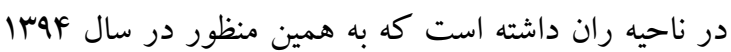
در يك مركز آموزشى درمانى بسترى بوده است كه در اين

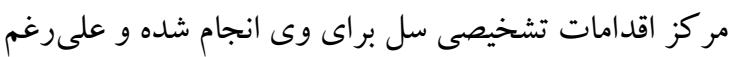

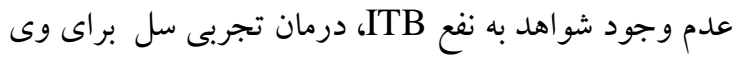
آغاز شده بود و با وجود دريافت يكك دوره كامل درمان

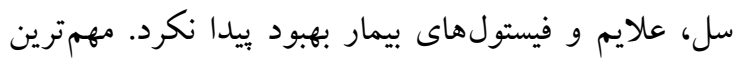

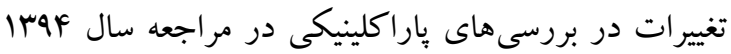
عبارتند از: در سونو گرافى جدار قدامى شكم، درد در ناحيه

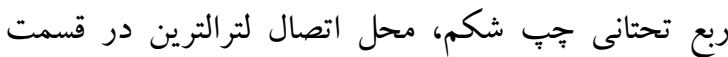

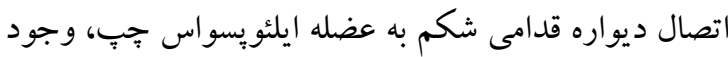
ضايعه هييو اكو به صورت توبولار همراه و شاخه شاخه به

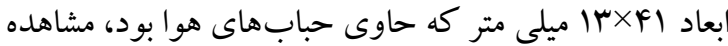
كرديد. در سى تى اسكن با تزريق ماده حاجب از طريق

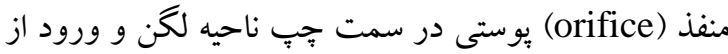
طريق يكك تراكت بزرگك به كولون سيخموئيد، فيستول با

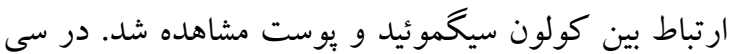

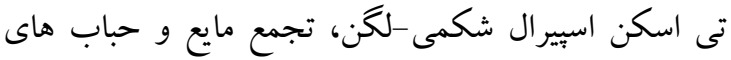

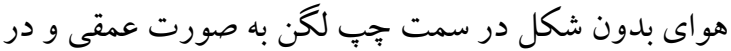

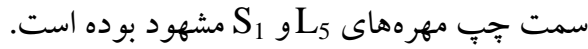
يافته هاى باراكلينيك در مراجعه اخير بيمار در سال يهوا به اين صورت است كه، در سى تى اسكن اسبيرال ريه و مدياستن بدون تزريق وجود كارديومگالى، شواهد شيشه

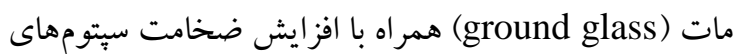
اينترلوبولار در لوب ميانى ريه راست و كدورتهاى ground glass

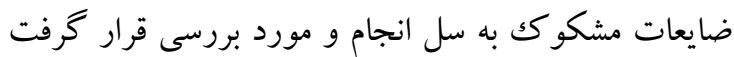

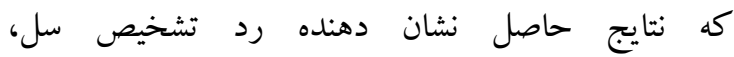
اكتينومايكوزيس و عفونتهاى قارجى بود. در واكنش رهن 


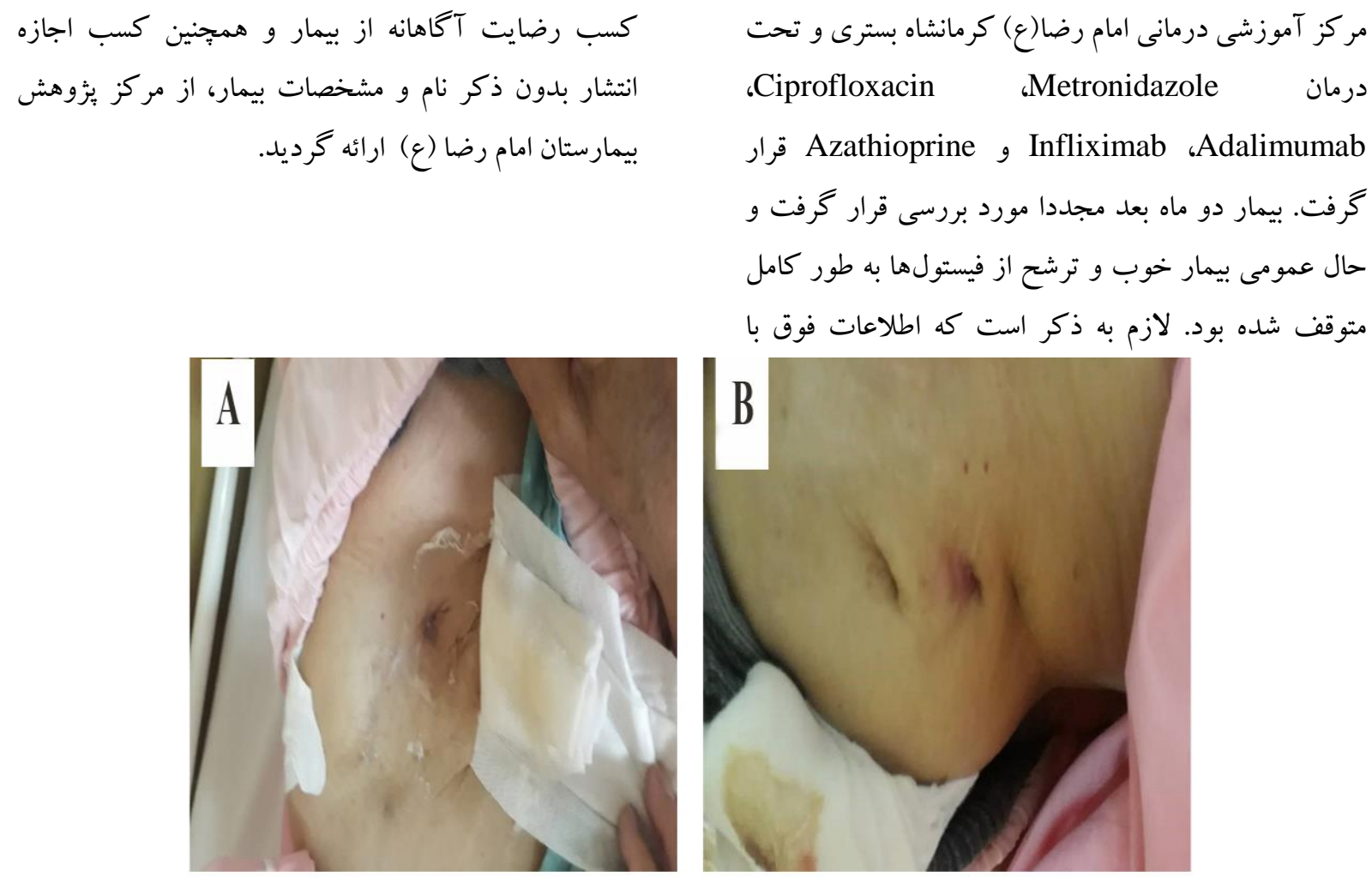

شكل ا. تصوير فيستولهاى بيمار. اين تصوير نشاندهندهى فيستولهاى ناحيه اينكوئينال (A) و گلوتئال جٍٍ (B) بيمار است كه همراه ترشحات مىباشد.

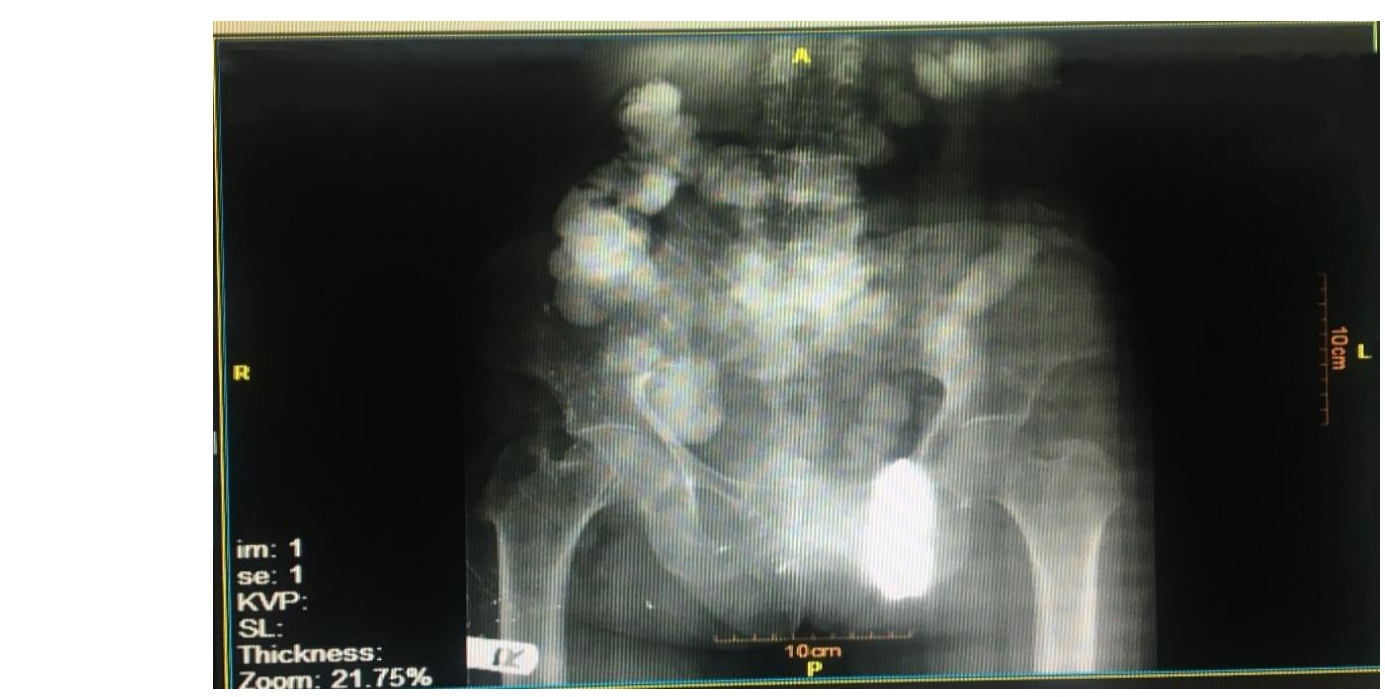

شكل r. كر افى باريم انماى بيمار. در اين تصوير الكوى تنخى در كولون بيمار قابل مشاهده است. به اين صورت كه تنكى خفيف با جدار منظم همراه با رتراكسيون جدار در سخمان كو تاهى از كولون سيخموئيد ديده مىشود. 
در مطالعهى P. Abadir و همكاران كه در سال 19 •r انجام شده است، بيمار مبتلا به سل رودهاى كه با شك به كرون

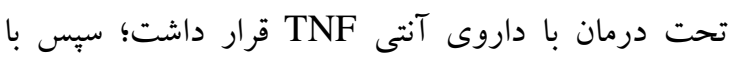
تشخيص شوك سيتيك يرفوريشن روده در بيمارستان بسترى گرديد. معرفى اين كيس توسط ئزوهشخران

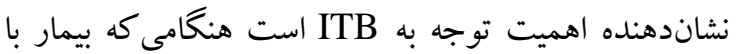

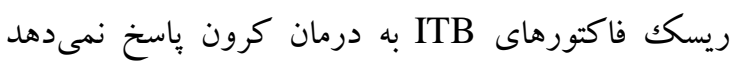
Kurnick و همكاران در مطالعهى خود كه با هدف گزارش جالش تشخيصى سل رودهاى و بيمارى كرون انجام شد، به اين نتيجه رسيدند كه ITB از مهم ترين تشخيص افتراقىهاى CD است. اما نكته حائز اهميت اين است كه آزمايشات تشخيصى عفونت پينهان سل به همراه

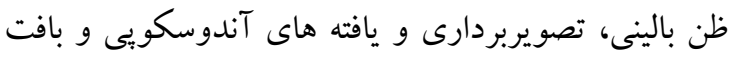
شناسى مى تواند در افتراق ITB از CD موثر باشد (Y (Y). بنابراين از آنجايى كه عود ييشرونده سل در حالى كه درمان

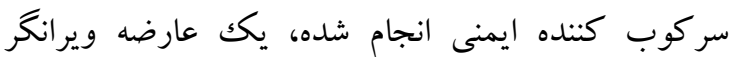

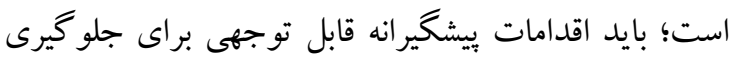
از آن انجام شود. به عنوان يكك روش، قبل از شروع درمان آنتى TNFاينترفرون خون (Quantiferon-TB Gold Test) و ام آر انترو كرافى انجام شود. همجِين لنفادنوياتى همراه با نكروز در CT شكم و لكن مىتواند به عنوان يك يافته بالينى مناسب در تشخيص افتراقى بيمارى كرون از سل رودهاى محسوب شود.

\section{نتيجه تيرى}

از مهمترين تشخيص افتراقىهاى سل رودهاى، بيمار كرون مىباشد؛ لذا علاوه بر بررسى بيمار از نظر سل رودهاى بايد با تهائ

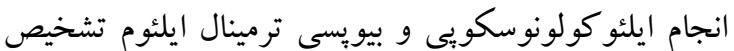
كرون براى بيمار رد يا تاييد گردد.
تشخيص افتراقى ITB و CD جالشى بسيار بِيجِيده و دشوار است. Limsrivilai و همكاران در يكك مطالعه متآناليز مدل Bayesian، حساسيت و اختصاصيت اين مدل در

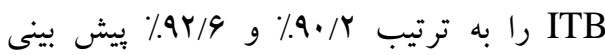

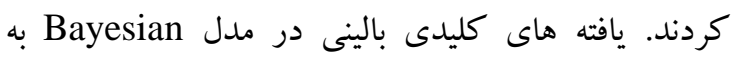
منظور تشخيص CD، عبارتند از بيمارى برى آنال،

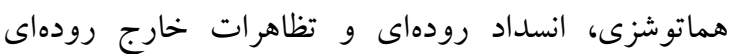
مىباشد. همجنين يافتهاى كليدى بالينى در اين مدل براى

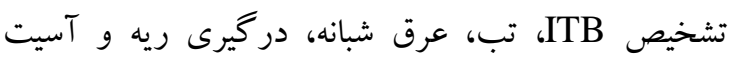

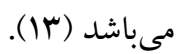
مطالعات متعددى در رابطه با استفاده از روش

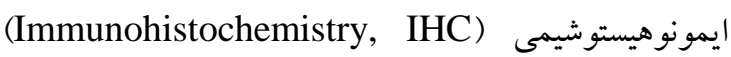
در افتراق تشخيصى CD از ITB، انجام شده است. در رنغك

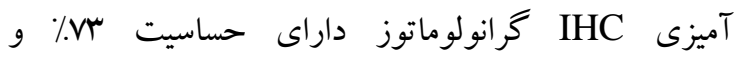
اختصاصيت سوء٪ در تشخيص افتراقى ITB از CD مىباشد. در اين تست از آنتى بادى VP-M3660 كه آنتىزن مايكوباكتريوم توبر كلوزيس را هدف قرار مئ دهى دهد، استفاده

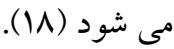
جالشى كه در مديريت كردن اين بيماران بيشروى ما است،

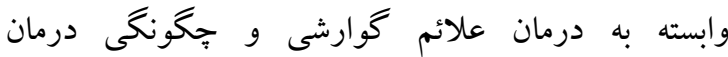
سركويخر ايمنى براى بيماران CD دارد. به اين صورت كه درمان آنتى (Tumor necrosis factor alpha, TNFدر بيمارانى كه سل ريوى همزمان دارند، احتمال عود مجدد سل را افزايش مىدهد (19). Castellotti زن باردارى را معرفى نمودند كه با تشخيص كرون به صورت طولانى مدت تحت درمان با استروئيدها قرار خرفته بود اما در نهايت بيمارى وى ITB تشخيص داده شد. يُزوهشگران بِ از انجام مطالعه به اين نتيجه رسيدند كه

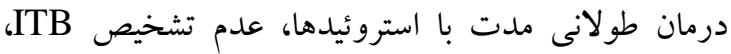
خصوصا در الكوى بافت شناسى آن را به دنبال دارد (·r).

هجلم علمى دانشكاه علوه دِزشكى كردستان / دوره بيست و شش / فرودين و ا(ديبهشت م.ع|| 


$$
\begin{aligned}
& \text { يشتيبانى مالى به طور انحصارى توسط كميته تحقيقات داخلى و عفونى بيمارستان امام رضا(ع) كرمانشاه جهت }
\end{aligned}
$$

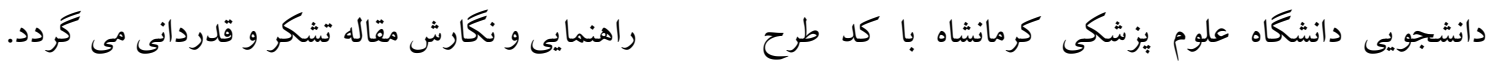

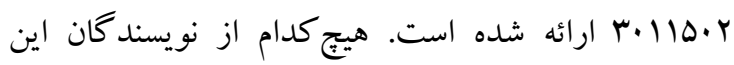

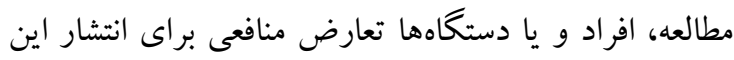

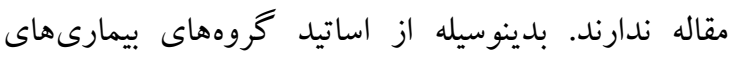

1.Fitzgerald DW, Sterling TR, Haas DW. Mycobacterium tuberculosis In: Mandell GL, Bennett JE, Dolin R, (eds). Principles and practice of infectious diseases. 7th ed. Philadelphila: Churchill Livingstone. 2010:3125-59.

2.World Health Organization. Global tuberculosis report. World Health Organization;2017.

3.Debi U, Ravisankar V, Prasad KK, Sinha SK, Sharma AK. Abdominal tuberculosis of the gastrointestinal tract: revisited. World J Gastroenterol. 2014;20(40):14831-40.

4.Horvath KD, Whelan RL. Intestinal tuberculosis: return of an old disease. Am J Gastroenterol. 1998;93(5):692-6.

5.Hussain T, Salamat A, Farooq MA, Hassan F, Hafeez M. Indications for endoscopic ultrasound and diagnosis on fine-needle aspiration and cytology. J Coll Physicians Surg Pak. 2009;19(4):223-7.

6.Özbülbül NI, Özdemir M, Turhan N. CT findings in fatal primary intestinal tuberculosis in a liver transplant recipient. Diagn Interv Radiol. 2008;14(4):221.

7.Shivashankar R, Tremaine WJ, Harmsen WS, Loftus Jr EV. Incidence and prevalence of Crohn's disease and ulcerative colitis in Olmsted County, Minnesota from 1970 through 2010. Clin Gastroenterol Hepatol. 2017;15(6):857-63.

8.Molodecky NA, Soon S, Rabi DM, Ghali WA, Ferris M, Chernoff G, et al. Increasing incidence and prevalence of the inflammatory bowel diseases with time, based on systematic review. Gastroenterology. 2012;142(1):46-54.

9.Zhou D, Ouyang Q, Xiong M, Zhang Y. Crohn's disease with positive Ziehl-Neelsen stain: Three case reports. Niger J Clin Pract. 2018;21(10):1387-90.

10.Lee SS, Kim AY, Yang SK, Chung JW, Kim SY, Park SH, et al. Crohn disease of the small bowel: comparison of CT enterography, MR enterography, and small-bowel follow-through as diagnostic techniques. Radiology. 2009;251(3):751-61.

11.Horton KM, Fishman EK. CT angiography of the GI tract. Gastrointestinal endoscopy. 2002;55(7):S37-41.

12.Jacene HA, Ginsburg P, Kwon J, Nguyen GC, Montgomery EA, Bayless TM, et al. Prediction of the need for surgical intervention in obstructive Crohn's disease by 18F-FDG PET/CT. J Nucl Med. 2009;50(11):1751-9.

13.Limsrivilai J, Shreiner AB, Pongpaibul A, Laohapand C, Boonanuwat R, Pausawasdi N, et al. Meta-analytic bayesian model for differentiating intestinal tuberculosis from Crohn's disease. Am J Gastroenterol. 2017;112(3):415.

14.Karateke F, Özyazıcı S, Menekşe E, Daş K, Özdoğan M. Unusual presentations of actinomycosis; anterior abdominal wall and appendix: report of three cases. Balkan Med J. 2013;30(3):315.

15.Triantopoulou C, Van der Molen A, Van Es AC, Giannila M. Abdominopelvic actinomycosis: spectrum of imaging findings and common mimickers. Acta Radiol Short Rep. 2014;3(2):2047981614524570.

16.Ertas IE, Gungorduk K, Ozdemir A, Emirdar V, Gokcu M, Dogan A, et al. Pelvic tuberculosis, echinococcosis, and actinomycosis: great imitators of ovarian cancer. Aust N Z J Obstet Gynaecol. 2014;54(2):166-71.

هجلم علمى دانشكاه علوم بِزشكى كردستان / دوره بيست و شش / فروردين و ا(ديبهشت مع|| 
17.Malikowski T, Mahmood M, Smyrk T, Raffals L, Nehra V. Tuberculosis of the gastrointestinal tract and associated viscera. J Clin Tuberc Other Mycobact Dis. 2018;12:1-8.

18. İnce AT, Güneş P, Şenateş E, Sezikli M, Tiftikçi A, Övünç O. Can an immunohistochemistry method differentiate intestinal tuberculosis from Crohn's disease in biopsy specimens?. Digestive diseases and sciences. 2011;56(4):1165-70.

19.Kim YJ, Kim YG, Shim TS, Koo BS, Hong S, Lee CK, et al. Safety of resuming tumour necrosis factor inhibitors in patients who developed tuberculosis as a complication of previous TNF inhibitors. Rheumatology. 2014;53(8):1477-81.

20.Castellotti P, Riccardi N, Ferrarese M, Canetti D, Fanti D, Forti E, et al. Intestinal tuberculosis versus Inflammatory Bowel Diseases: a never-ending challenge. The new Microbiologica. 2020;43(3). 21.Abadir AP, Han JY, Youssef FA. Intestinal Tuberculosis Masquerading as Crohn's Disease? A Case of Disseminated Tuberculosis after Anti-TNF Therapy for Suspected Crohn's Disease. Case reports in gastrointestinal medicine. 2019; 14;2019.

22.Kurnick A, Bar N, Maharshak N. Intestinal Tuberculosis and Crohn's Disease is Always a Diagnostic Challenge: A Case Report and Review of the Literature on the Importance of Fecal Mycobacterial Cultures and the Limitations of Latent Infection Testing. Cureus. 2019;11(9). 